\section{Discovery of a Living Metasequoia in China}

UNDOUBTEDLY one of the most interesting recent additions to our knowledge of the Chinese flora is the discovery of a 'new' conifer thought to be congeneric with Mesozoic fossil forms originally ascribed to Sequoia but now placed in a separate genus Metasequoia, as $M$. Heerii, $M$. japonica, $M$. disticha and $M$. chinensis. The living species of Metasequoia was discovered in north-eastern Szechwan in 1945, but is now known to occur more abundantly in Hupeh province. It occupies, however, only a limited area, and there is a grave danger that felling of the trees may lead to its extinction. Thanks, however, to the enterprise of the Arnold Arboretum of Harvard University and the co-operation of Chinese botanists, a special expedition last year obtained an ample supply of seed, and seedlings are now being raised in Britain as well as in the United States. The tree grows to a height of at least $115 \mathrm{ft}$., with a trunk diameter of at least $7 \frac{1}{2} \mathrm{ft}$., and is deciduous. In general appearance it is not unlike a Glyptostrobus. An account by Prof. E. D. Merrill of the discovery and introduction of this new Metasequoia has recently been published in Arnoldia (8, 1 ; March 1948).

\section{British Fauna}

THE Linnean Society of London is to be congratulated upon initiating a very useful piece of work in its "Synopses of the British Fauna", of which the first number was published in January 1944 and the most recent, No. 7, in 1947. The need for such synopses, particularly in the groups which do not attract the ordinary collector, like, say, Lepidoptera and Coleoptera, has long been felt by zoologists, naturalists and ecologists. The numbers so far published in order of appearance are: (1) Opiliones; (2) Caprellidea; (3) Gammaridæ; (4) Freshwater Bivalves; (5) Freshwater Bivalves (Unionacea); (6) Lumbricidæ; and (7) Talitridæ. The synopses are well printed, illustrated and provided with keys which in the two groups that have been used by the reviewer on several occasions are not difficult to use and do work. The price is reasonable, $2 s .6 d$., save for the largest, which is 5s. Individual numbers will naturally appeal to workers in their particular fields ; but no institution that is likely to be concerned, however remotely, with faunistic work can afford to be without the complete set. It is to be hoped that the paper restriction will not slow down the rate of publication, or lead to the printing of insufficient copies of these synopses.

\section{Research at the University of Birmingham}

THe eighteenth annual report of the Joint Standing Committee for Research of the University of Bir. mingham, which covers the sessions 1938-39 to 1946-47, is a reference document of exceptional interest. The first section, covering the years from 1938-39 to 1945-46, gives a summary of the research carried out in the various departments of the Faculties of Science, Arts, Medicine and Commerce and also by the University Library, the Board of Research for Mental Disease, the Cancer Research Laboratory, and the Radiotherapy Department, Birmingham United Hospital. The summaries or notes on these researches are supported by full lists of publications under the Departments concerned. The second section of the report, covering the session 1946-47, in addition to a like list of publications embodying results of research completed in 1946-47, lists the personnel of the Committee, the research funds avail- able for the session 1946-47, the conditions and procedure relating to applications for grants, the subjects of research towards which grants-in-aid have been made by the Committee and also other subjects of research during the session.

\section{Atmosphere of Mars}

THE December issue of Sky and Telescope contains a short note on the atmosphere of Mars, which describes the work of Dr. G. P. Kuiper, of the Yerkes and McDonald Observatories, on this subject. Using an infra-red spectrometer employing a Cashman lead-sulphide cell a thousand times more sensitive than any previous instruments of this type, Dr. Kuiper has examined the spectra of celestial objects at wave-lengths of $1-2.5$ microns, and has found that the atmosphere of Mars contains at least as much carbon dioxide as does the earth's atmosphere. Methane and ammonia appear to be absent. Dr. Kuiper believes that the Martian polar caps are probably ordinary snow and clouds of water vapour, and he was hoping to test this on February 17 when Mars was at opposition and near aphelion. If the polar cap visible at that time is sufficiently large for his test, it will be possible to measure the amount of water vapour on the planet with the new instrument.

\section{Catalogue of Medical Films}

THF Catalogue of Medical Films compiled by the Royal Society of Medicine and the Scientific Film Asso ziation, which are referred to in the catalogue as RSM and SFA respectively (ASLIB, 52 Bloomsbury Street, W.C.1, 1948. 7s. 6d. and 6s. to members of ASLIB and SFA), is a very useful small volume. It is the outcome of collaboration, suggested by the Royal Society of Medicine when it was considering the formation of a library of medical films. By March, 1946, more than 1,200 titles of films had been collected from lists held by commercial firms, medical schools and societies, university departments and private individuals. All the material thus collected has been entrusted to the care of the Scientific Film Association, to which all inquiries about it should be addressed (34 Soho Square, London, W.1). Eight hundred of the films have been viewed, and Part 1 of the catalogue groups them by subjects and catalogue numbers. Part 2 gives details of the availability of two hundred of the films. It shows that they come from various sources in Britain, Europe and the United States, and range from elementary instructional films suitable for health education of the lay public to films of difficult surgical operations and similar subjects suitable only for medical and scientific audiences. All the films listed in Part 2 are available, and more than one copy of each exists. Many other films not listed in Part 1 are also now available, and details of these can be obtained from the medical cataloguer of the Scientific Film Association.

\section{Origins of Central American Culture}

IN "Some Implications of the Ceramic Complex of La Venta" (Smithsonian Misc. Coll., 107, No. 8), Dr. Philip Drucker presents an interim report on this important site in southern Mexico. The name has recently been applied to an early culture found at this and neighbouring sites, but be prefers the older term 'Olmec', which was abandoned owing to its association with a tribe inhabiting the area in historic times, because La Venta does not provide the most 